\title{
Модель влияния смещения затвора при ионизирующем облучении МОП-структур
}

\author{
(C) О.В. Александров, С.А. Мокрушина \\ Санкт-Петербургский государственный электротехнический университет „ЛЭТИ“, \\ 197376 Санкт-Петербург, Россия \\ E-mail: Aleksandr_ov@mail.ru \\ Поступила в Редакцию 25 июня 2019 г. \\ В окончательной редакции 10 сентября 2019 г. \\ Принята к публикации 30 сентября 2019 г.
}

\begin{abstract}
Разработана новая количественная модель влияния смещения затвора при ионизирующем облучении на пороговое напряжение МОП-структур, базирующаяся на учете захвата дырок со всего объема подзатворного диэлектрика в тонком пограничном слое с безводородными и водородосодержащими ловушками на границе с кремниевой подложкой. Модель позволяет удовлетворительно описать плавный рост порогового напряжения с напряжением смещения на затворе - примерно линейный от дозы для поверхностной составляющей и нелинейный для объемной составляющей. Сдвиг порогового напряжения при отрицательном напряжении на затворе моделируется на основе учета генерации дырок в пограничном слое под действием ионизирующего облучения.
\end{abstract}

Ключевые слова: ионизирующее облучение, МОП-структура, оксидные ловушки, поверхностные состояния, моделирование.

DOI: $10.21883 /$ FTP.2020.02.48902.9195

\section{1. Введение}

Влиянию ионизирующего облучения на МОП-приборы посвящено большое количество работ (см. монографии $[1,2]$ и обзоры [3-5]) и разработаны качественные [6,7] и количественные [8-11] модели. Однако некоторые особенности образования поверхностных состояний (ПС) на межфазной границе (МФГ) $\mathrm{Si}-\mathrm{SiO}_{2}$ и положительного объемного заряда (O3) в диэлектрике под действием ионизирующего облучения остаются не вполне ясными. Так, в модели МакЛина [6] полагается, что захват дырок, генерируемых ионизирующим облучением в составе электронно-дырочных пар, на водородосодержащие ловушки и освобождение ионов $\mathrm{H}^{+}$происходят в объеме диэлектрика. В этом случае с увеличением напряженности электрического поля $(E)$ увеличивается энергия дырок и можно ожидать роста ПС и ОЗ. Однако в структурах с поликремниевым затвором после начального роста при $E>(1-2) \mathrm{MB} /$ см наблюдается падение ПС и О3 по закону, близкому к $E^{-0.5}$ [7]. На основе этого результата Шанефельт с соавт. [7] предложили качественную $\mathrm{HT}^{2}$ модель (hole trapping/hydrogen transport), в которой взаимодействие дырок с ловушками и освобождение водорода происходит не в объеме $\mathrm{SiO}_{2}$, а в тонком пограничном слое вблизи МФГ $\mathrm{Si}-\mathrm{SiO}_{2}$ толщиной около 10 нм. Действительно, установлено, что дырочные ловушки в термическом диоксиде кремния распределены неоднородно по толщине и располагаются в пограничном слое толщиной от 3 до $40 \mathrm{HM}$ [12]. Лимитирующей стадией в обеих моделях [6,7] полагается транспорт ионов $\mathrm{H}^{+}$. Однако представляется маловероятным, что в тонком пограничном слое, соглас- но $\mathrm{HT}^{2}$-модели [7], лимитирующим процессом может быть транспорт ионов $\mathrm{H}^{+}$. Более вероятным представляется преобразование захваченных дырок в ПС, как это было показано в работах $[13,14]$. Общепризнанно, что ключевую роль в образовании ПС и О3 играет захват дырок на ловушки. Полагаем, что при этом скорость захвата дырок может определяться не только их объемной концентрацией, как это полагалось в моделях [8-11], но и скоростью стока дырок в пограничный слой.

В настоящей работе предложена новая количественная модель образования ПС и О3 в МОП-структурах под действием ионизирующего облучения с учетом стока дырок в пограничный слой со всего объема диэлектрика с последующим их захватом на ловушки этого слоя.

\section{2. Уравнения модели}

При ионизирующем облучении (ИО) МОП-структуры в подзатворном диэлектрике происходит генерация электронно-дырочных пар. Оставшиеся после взаимной рекомбинации электроны, имеющие высокую подвижность, стекают на межфазные границы с кремниевой подложкой и затвором. Дырки, имеющие малую подвижность, захватываются на ловушки. В модели $[10,11]$ нами полагалось, что основными дырочными ловушками в подзатворном диоксиде кремния являются нейтральные безводородные и водородосодержащие дефекты $T^{0}$ и $\mathrm{TH}^{0}$, где $T-$ дефект структуры диоксида кремния типа $\mathrm{O}_{3} \equiv \mathrm{Si} \bullet$, обусловленный кислородной вакансией. Основные реакции, происходящие в подзатворном диэлектрике при ИО, следующие. При захвате дырки 
безводородной дырочной ловушкой образуется положительный объемный заряд

$$
T^{0}+h^{+} \stackrel{k 1}{\rightarrow} T^{+} .
$$

Поверхностные состояния образуются в соответствии с эмпирической моделью Мак-Лина [6] при посредстве положительного иона водорода (протона), который освобождается при захвате дырки водородосодержащей ловушкой по реакции

$$
\mathrm{TH}^{0}+h^{+} \stackrel{k 2}{\longrightarrow} T^{0}+H^{+} .
$$

Этот положительный ион водорода мигрирует к МФГ $\mathrm{Si}-\mathrm{SiO}_{2}$, где освобождает от водорода (депассивирует) $P_{b}$-центр $\left(\mathrm{Si}_{3} \equiv \mathrm{Si} \bullet\right)$ по реакции

$$
\equiv \mathrm{SiH}+\mathrm{H}^{+} \rightarrow \equiv \mathrm{Si} \bullet+\mathrm{H}_{2} .
$$

Заряд на поверхностном состоянии устанавливается в соответствии с уровнем и типом легирования кремниевой подложки и потенциалом на затворе. Учитывается нейтрализация положительно заряженной ловушки при захвате электрона:

$$
T^{+}+e^{-\stackrel{k 3}{\rightarrow}} T^{0}
$$

Реакции с образованием и участием нейтральных атомов водорода $\mathrm{H}^{0}$ в настоящей модели не рассматриваем, поскольку было показано, что нейтральное зарядовое состояние $\mathrm{H}^{0}$ является нестабильным как в $\mathrm{SiO}_{2}$ [15], так и на МФГ $\mathrm{Si}-\mathrm{SiO}_{2}[16]$.

Поведение дырок и электронов в объеме подзатворного диэлектрика МОП-структуры при ИО описываем системой диффузионно-кинетических уравнений непрерывности и уравнением Пуассона, учитывающими приведенные выше процессы в подзатворном диэлектрике:

$$
\begin{gathered}
\frac{\partial p}{\partial t}=D_{p} \frac{\partial^{2} p}{\partial x^{2}}-\mu_{p} \frac{\partial}{\partial x}(p E)-\left(k_{1} C_{T}^{0}+k_{2} C_{T H}^{0}\right) p+G, \\
\frac{\partial n}{\partial t}=D_{n} \frac{\partial^{2} n}{\partial x^{2}}-\mu_{n} \frac{\partial}{\partial x}(n E)-k_{3} C_{T}^{+} n+G \\
\frac{\partial^{2} V}{\partial x^{2}}=-\frac{q}{\varepsilon \varepsilon_{0}}\left(C_{T}^{+}+C_{H}^{+}+p-n\right)
\end{gathered}
$$

где $x$ - координата, отсчитываемая от МФГ подзатворного диэлектрика с кремнием (при $x=0)$ до МФГ с затвором (при $x=d, d-$ толщина подзатворного диэлектрика); $t$ - время облучения; $n$ и $p-$ концентрации свободных электронов и дырок соответственно; $D_{n}$ и $\mu_{n}-$ коэффициенты диффузии и подвижность электронов $\left(\mu_{n}=20 \mathrm{~cm}^{2} / \mathrm{B} \cdot \mathrm{c}[17]\right) ; D_{p}$ и $\mu_{p}-$ коэффициент диффузии и подвижность дырок $\left(D_{p}=2 \cdot 10^{-7} \mathrm{~cm}^{2} / \mathrm{B} \cdot \mathrm{c}[18]\right)$; $C_{T}^{0}$ и $C_{T}^{+}-$концентрации нейтральных и положительно заряженных безводородных ловушек; $C_{T H}^{0}-$ концентрация нейтральных водородосодержащих ловушек; $C_{H}^{+}-$ концентрация положительных ионов водорода; $V$ - распределение потенциала в диоксиде кремния, $E$ - напряженность электрического поля, $E=-d V / d x ; q-$ заряд электрона; $\varepsilon$ - относительная диэлектрическая проницаемость диоксида кремния $(\varepsilon=3.9) ; \varepsilon_{0}-$ диэлектрическая постоянная, $G$ - темп генерации электроннодырочных пар. Темп генерации электронно-дырочных пар $G$ определяется мощностью радиационной дозы $F$, коэффициентом генерации электронно-дырочных пар $k_{g}$ и вероятностью $f_{y}(E)$ разделения пар электрическим полем до их начальной рекомбинации: $G(E)=F k_{g} f_{y}(E)$. Темп генерации рассчитывался по [19] при коэффициенте генерации электронно-дырочных пар рентгеновским облучением, $k_{g}=1.4 \cdot 10^{-6}$ Кл $\cdot \mathrm{cm}^{-3} /$ рад.

В отличие от моделей [8-11], в настоящей модели полагаем, что реакции (1)-(4) происходят не в объеме диэлектрика, а в тонком пограничном слое и их скорости определяются не объемной концентрацией дырок, остающихся в диэлектрике, а их количеством $Q_{p}$, захваченным пограничным слоем, включающем МФГ. Это количество пропорционально потоку дырок, стекающих со всего объема подзатворного диэлектрика, где они генерируются ионизирующим облучением, на МФГ $\mathrm{Si}-\mathrm{SiO}_{2}$ :

$$
Q_{p}=k_{p} j_{p}(0) l,
$$

где $l-$ толщина пограничного слоя, $k_{p}-$ коэффициент захвата дырок пограничным слоем, $j_{p}(0)-$ поток дырок на МФГ $\mathrm{Si}-\mathrm{SiO}_{2}$ (при $\left.x=0\right)$,

$$
j_{p}=-D_{p} \frac{\partial p}{\partial x}+\mu_{p} p E
$$

В уравнениях баланса для реакций (1)-(4) переходим от объемных концентраций к полным концентрациям $\left(Q_{T}^{0}=C_{T}^{0} l ; Q_{T}^{+}=C_{T}^{+} l ; Q_{T H}^{0}=C_{T H}^{0} l\right)$ и используем эффективную концентрацию захваченных дырок $p^{*}=Q_{p} / l=k_{p} j_{p}(0)$ :

$$
\begin{gathered}
\frac{\partial Q_{T}^{+}}{\partial t}=k_{1} Q_{T}^{0} p^{*}-k_{3} Q_{T}^{+} n, \\
\frac{\partial Q_{T}^{0}}{\partial t}=\left(k_{2} Q_{T H}^{0}-k_{1} Q_{T}^{0}\right) p^{*}+k_{3} Q_{T}^{+} n, \\
\frac{\partial Q_{H}^{+}}{\partial t}=-\frac{\partial Q_{T H}^{0}}{\partial t}=k_{2} Q_{T H}^{0} p^{*} .
\end{gathered}
$$

В уравнении (12) не учитываем диффузионный и дрейфовый члены вследствие малой толщины пограничного слоя по сравнению с диффузионной и дрейфовой длиной ионов $\mathrm{H}^{+}$за время облучения. Полагаем, что в начальный момент времени концентрации всех компонентов нулевые:

$$
n(x, 0)=p(x, 0)=0 ; \quad Q_{T}^{+}(x, 0)=Q_{H}^{+}(x, 0)=0,
$$

кроме исходных концентраций нейтральных безводородных и водородосодержащих дырочных ловушек:

$$
Q_{T H}^{0}(0)=Q_{T H 0}^{0} ; \quad Q_{T}^{0}(0)=Q_{T 0}^{0} .
$$


Уравнения (5)-(7) решались при граничных условиях, соответствующих нулевой концентрации свободных носителей на обеих межфазных границах:

$$
p(0, t)=p(d, t)=n(0, t)=n(d, t)=0 .
$$

К затвору относительно подложки приложено напряжение $V_{g}$ :

$$
V(0, t)=0 ; \quad V(d, t)=V_{g} .
$$

Сдвиг порогового напряжения под действием облучения $\left(\Delta V_{t h}\right)$ складывается из объемной $\left(\Delta V_{o t}\right)$ и поверхностной $\left(\Delta V_{i t}\right)$ составляющих:

$$
\Delta V_{t h}=\Delta V_{o t}+\Delta V_{i t}=-\left(Q_{o t}+Q_{i t}\right) / C_{o x},
$$

где $Q_{o t}$ - эффективный объемный заряд, $Q_{o t}=Q_{T}^{+}$; $Q_{i t}$ - заряд ПС; $C_{o x}$ - удельная емкость диэлектрика, $C_{o x}=\varepsilon \varepsilon_{0} / d$. Полагаем, что заряд ПС, образующихся при облучении, определяется суммарным количеством ионизованного водорода, образующегося в пограничном слое, т.е. каждый ион водорода, стекающий на $\mathrm{MФГ} \mathrm{Si}-\mathrm{SiO}_{2}$, приводит к депассивации одного ПС: $\left|Q_{i t}\right|=Q_{H}^{+}$.

Параметрами модели, помимо исходных концентраций водородосодержащих и безводородных дырочных ловушек $Q_{T H 0}^{0}$ и $Q_{T 0}^{0}$, являются константы скоростей реакций $(1),(2),(4): k_{1,2}=\sigma_{p 1,2} v_{t h} D_{p} / D_{n} ; k_{3}=\sigma_{n 3} v_{t h}$, где $\sigma_{p}$ и $\sigma_{n}$ - сечения захвата дырок и электронов соответственно, $v_{t h}$ - тепловая скорость электронов, $v_{t h} \cong 10^{7} \mathrm{~cm} / \mathrm{c}$. Учитывалась зависимость от напряженности электрического поля сечений захвата дырок и электронов по $[20,21]$ при значениях сечения захвата в слабых полях дырок $\sigma_{p 01}=2.1 \cdot 10^{-13} \mathrm{~cm}^{2}$, $\sigma_{p 02}=1.4 \cdot 10^{-14} \mathrm{~cm}^{2}$ и электронов $\sigma_{n 03}=8 \cdot 10^{-14} \mathrm{~cm}^{2}$ при коэффициенте захвата дырок пограничным слоем $k_{p}=0.5 \mathrm{c} / \mathrm{cm}$.

\section{3. Расчеты по модели}

Система уравнений модели (5)-(7) и (10)-(12) с граничными условиями (9), (15), (16) и начальными условиями (13), (14) с учетом (8), (17) решались численно с использованием неявной разностной схемы при задании различных напряжений на затворе. Изменение концентраций компонентов в пограничном слое в зависимости от дозы ИО показано на рис. 1. Как видно из рисунка, концентрации $C_{T H 0}^{0}$ и $C_{T 0}^{0}$ с ростом дозы (или времени облучения) падают, тогда как концентрации $C_{T}^{+}$и $C_{H}^{+}$растут. При выбранных параметрах рост $C_{H}^{+}$примерно линейный, тогда как рост $C_{T}^{+}-$нелинейный. Концентрации дырок и электронов в объеме оксида устанавливаются за короткое время на стационарном уровне $\left(p \cong 3.3 \cdot 10^{8} \mathrm{~cm}^{-3}\right.$, $\left.n \cong 1.3 \cdot 10^{2} \mathrm{~cm}^{-3}\right)$.

Решения сравнивались с экспериментальными зависимостями поверхностной $\Delta V_{i t}$ и объемной $\Delta V_{0 t}$ составляющих сдвига порогового напряжения от смещения

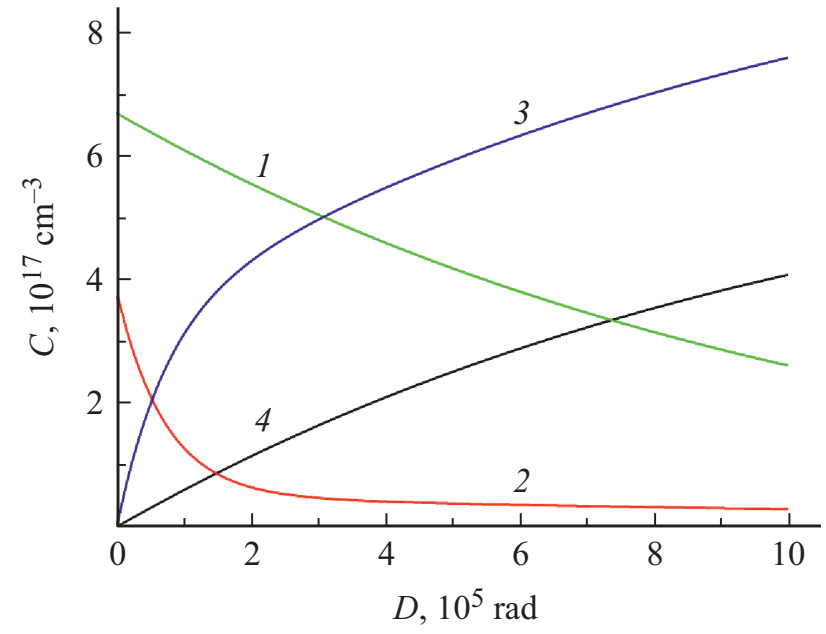

Рис. 1. Изменение концентраций компонентов в пограничном слое от дозы ИО: $1-C_{T H 0}^{0}, 2-C_{T 0}^{0}, 3-C_{T}^{+}, 4-C_{H}^{+}$. Расчет при $Q_{T H 0}^{0}=7 \cdot 10^{11} \mathrm{~cm}^{-2} ; Q_{T 0}^{0}=3.8 \cdot 10^{11} \mathrm{~cm}^{-2}\left(V_{g}=+10 \mathrm{~B}\right.$, $d=120 \mathrm{HM})$.

затвора (или напряженности электрического поля) в процессе ИО. Экспериментальные $n$ - и $p$-канальные МОП-транзисторы изготавливались соответственно в $n$ - и $p$-карманах кремниевых структур (уровни легирования $5 \cdot 10^{15} \mathrm{~cm}^{-3}$ и $1 \cdot 10^{16} \mathrm{~cm}^{-3}$ соответственно) ориентации (100) с диэлектрической изоляцией с $n^{+}$-поликремниевым затвором и толщиной подзатворного термического $\mathrm{SiO}_{2}$ 70, 120 и 150 нм. Термический оксид кремния выращивался при температурах $900-1000^{\circ} \mathrm{C}$ в среде сухого кислорода с добавлением $\sim 1 \%$ сухого или влажного $\mathrm{HCl}$. Транзисторы подвергались рентгеновскому облучению $\mathrm{Cu} K_{\alpha}$ с энергией 40 кэВ и мощностью дозы 300 рад/с. Дозы облучения составляли от $1 \cdot 10^{5}$ до $1 \cdot 10^{6}$ рад при подаче на затвор относительно подложки смещения от -10 до $+10 \mathrm{~B}$. Разделение сдвига порогового напряжения $\left(\Delta V_{t h}\right)$ на поверхностную $\left(\Delta V_{i t}\right)$ и объемную $\left(\Delta V_{o t}\right)$ составляющие проводился по методу середины запрещенной зоны [22].

Экспериментальные зависимости $\Delta V_{i t}$ и $\Delta V_{o t}$ от напряжения на затворе $V_{g}$ для $n$-канальных транзисторов при разных дозах ИО показаны значками на рис. 2, $a$ и $b(d=120 \mathrm{Hм}$, сухой $\mathrm{HCl})$. Сплошными линиями $\left(1^{\prime}-4^{\prime}\right)$ на рис. 2, $a$ и $b$ показан расчет при тех же параметрах, что и на рис. 1. При увеличении положительного напряжения на затворе $\left(V_{g}>0\right)$ наблюдается монотонный рост $\Delta V_{i t}$ и $\left|V_{o t}\right|$. Отметим, что рост $\Delta V_{i t}$ с дозой на рис. 2, $a$ примерно линеен, тогда как рост $\Delta V_{o t}(D)$ на рис. $2, b$ не линеен. Этот результат соответствует примерно линейному росту зависимости $C_{H}^{+}(D)$ (см. кривую 4 на рис. 1) и нелинейному росту зависимости $C_{T}^{+}(D)$ (см. кривую 3 на рис. 1 ). Как видно из рис. $2, a, b$ при $V_{g}>0$ достигается удовлетворительное соответствие расчета с экспериментом. При отрицательном напряжении на затворе $\left(V_{g}<0\right)$ поток дырок на 


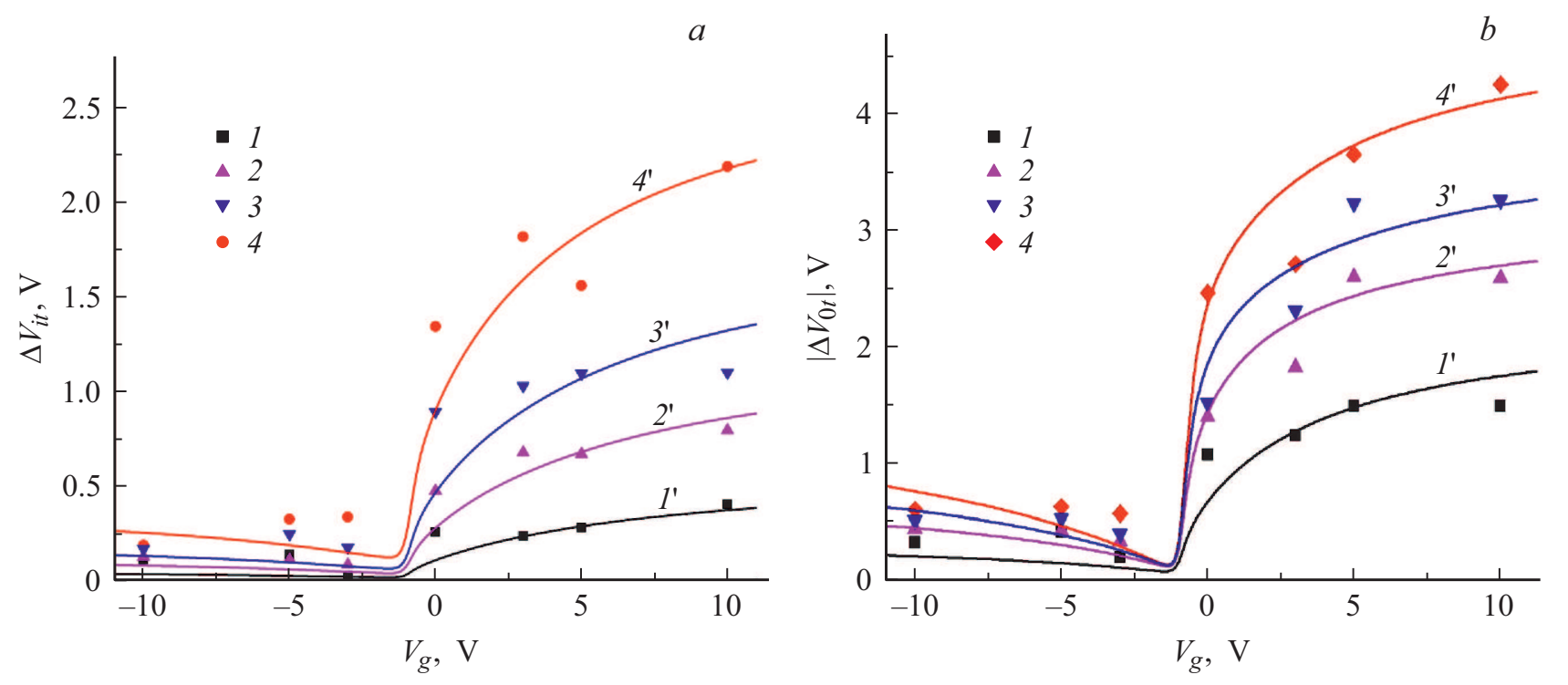

Рис. 2. $a, b-$ зависимость поверхностной $\Delta V_{i t}(1)$ и объемной $\Delta V_{o t}(b)$ составляющих сдвига порогового напряжения $n$-МОП-транзисторов от напряжения на затворе при дозе ИО, рад: $1,1^{\prime}-1 \cdot 10^{5} ; 2,2^{\prime}-3 \cdot 10^{5} ; 3,3^{\prime}-5 \cdot 10^{5} ; 4,4^{\prime}-1 \cdot 10^{6} ; 1-4-$ эксперимент; $l^{\prime}-4^{\prime}$ - расчет при $Q_{T H 0}^{0}=7 \cdot 10^{11} \mathrm{~cm}^{-2} ; Q_{T 0}^{0}=3.8 \cdot 10^{11} \mathrm{~cm}^{-2}, l=10 \mathrm{Hм}(d=120 \mathrm{HM}$, сухой $\mathrm{HCl})$.

внутреннюю МФГ при $x=0$ резко падает, поскольку дырки устремляются к затвору при $x=d$, соответственно резко падают $\Delta V_{o t}$ и $\Delta V_{i t}$. Ненулевые значения $\Delta V_{o t}$ и $\Delta V_{i t}$ при отрицательном смещении затвора можно объяснить в рамках модели тем, что небольшая часть генерируемых при ИО дырок образуется в пограничном слое, где и участвует в реакциях (1)-(4). В этом

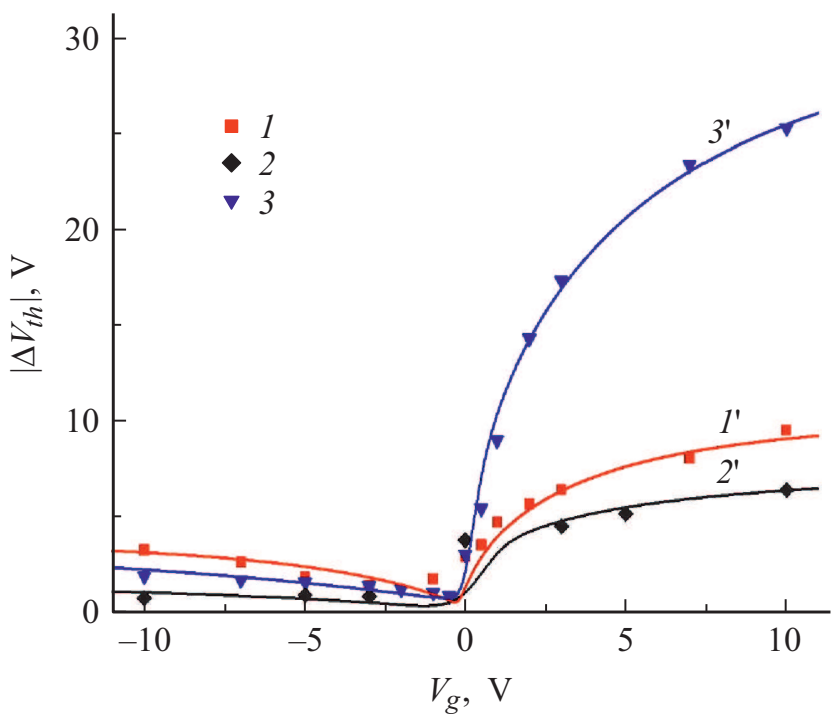

Рис. 3. Влияние толщины оксида кремния на зависимость сдвига порогового напряжения $p$-МОП-транзисторов от напряжения на затворе при ИО. Толщина оксида, нм: $1,1^{\prime}-$ $70 ; 2,2^{\prime}-120 ; 3,3^{\prime}-150 ; 1-3-$ эксперимент; $1,3-$ влажный $\mathrm{HCl}, 2-$ сухой $\mathrm{HCl} ; 1^{\prime}-3^{\prime}-$ расчет при $Q_{T H 0}^{0}, \mathrm{~cm}^{-2}$ : $1^{\prime}, 3^{\prime}-2.6 \cdot 10^{12}, 2^{\prime}-7 \cdot 10^{11} ; l, \mathrm{HM}: 1^{\prime}-20 ; 2^{\prime}, 3^{\prime}-10$ $\left(Q_{T 0}^{0}=3.8 \cdot 10^{11} \mathrm{~cm}^{-2}, D=1 \cdot 10^{6}\right.$ рад). случае в эффективной концентрации дырок, захваченных пограничным слоем, появляется добавка:

$$
\Delta p^{*}\left(V_{g}<0\right)=k_{p} \int_{0}^{l} G(E) d x \cong k_{p} G(x=l) l .
$$

С учетом этого положения проведен расчет при отрицательных смещениях затвора (кривые $1^{\prime}-4^{\prime}$ на рис. 2, $a$ и $b$ ), дающих при $V_{g}<0$ удовлетворительное соответствие расчета с экспериментом при $l=10$ нм. При положительном смещении затвора ширина пограничного слоя практически не оказывала влияния на решение.

Сдвиг порогового напряжения зависит от толщины подзатворного диэлектрика. На рис. 3 показаны зависимости сдвига порогового напряжения $\Delta V_{t h}$ для $p$-канальных транзисторов от напряжения на затворе $V_{g}$ при разных толщинах подзатворного оксида, полученного с использованием влажного (значки 1,3 ) и сухого (значки 2) $\mathrm{HCl}$ В случае влажного $\mathrm{HCl}$ соответствие расчетов (кривые $1^{\prime}, 3^{\prime}$ ) с экспериментом получено при полной концентрации $Q_{T H 0}^{0}$, в $\sim 4$ раза большей, чем в случае сухого $\mathrm{HCl}$ (кривая $2^{\prime}$ ) при той же концентрации $Q_{T 0}^{0}$. Отметим, что расчетная зависимость $\Delta V_{t h}$ от толщины подзатворного оксида вида $\Delta V_{t h} \sim d^{n}$ имеет показатель степени $n$, плавно изменяющийся от $n \cong 2$ при малых дозах ИО и толщинах диэлектрика $\left(D=10^{5}\right.$ рад, $d=10$ нм) до $n \cong 1$ при больших дозах ИО и толщинах $\left(D=10^{6}\right.$ рад, $\left.d=1000 \mathrm{Hм}\right)$.

\section{4. Обсуждение}

В настоящей работе модель с пограничным слоем описывает плавный рост обеих составляющих сдвига 
порогового напряжения $\Delta V_{i t}$ и $\Delta V_{o t}$ с ростом $V_{g}$ до $10 \mathrm{~B}$ (см. рис. 2, $a$ и $b$ ), что соответствует напряженности электрического поля $E=(0.6-1.4) \mathrm{MB} / \mathrm{cm}$. Ранее монотонный рост порогового напряжения наблюдался на МОП-структурах с Al-затвором [23,24] вплоть до $E=5 \mathrm{MB} / \mathrm{cm}$ [24], тогда как на МОП-структурах с поликремниевым затвором начальный рост порогового напряжения сменялся падением при $E>(1-2) \mathrm{MB} / \mathrm{cm} \quad[7,24,25]$. В работе [7] падение обеих составляющих сдвига порогового напряжения наблюдалось также и на МОП-структурах с Al-затвором. T. е. причина разного поведения $\Delta V_{i t}$ и $\Delta V_{o t}$ от $V_{g}$ лежит, по-видимому, не в материале затвора, а в технологии получения подзатворного диэлектрика.

Падение $\Delta V_{i t}$ и $\Delta V_{o t}$ с ростом $V_{g}$ при полях выше (1-2) MB/см связывалось в работах [7,24] с полевой зависимостью сечения захвата дырок $\sigma_{p}(E) \sim E^{-0.5}$. На этом основании Шанифелт с соавт. [7] предложили качественную $\mathrm{HT}^{2}$ модель образования поверхностных состояний, в которой ключевую роль играет захват дырок на ловушки вблизи МФГ с кремнием (при $V g>0$ ) или вблизи МФГ с затвором (при $V_{g}<0$ ). Однако, как было показано нами в [11], падение $\Delta V_{i t}$ и $\Delta V_{o t}$ с ростом $V_{g}$ вызвано не полевой зависимостью сечения захвата дырок, а уменьшением объемной концентрации дырок в диэлектрике из-за роста дрейфового члена в стоке дырок на МФГ $\mathrm{Si}-\mathrm{SiO}_{2}$ (при $V_{g}>0$ ). С этим же обстоятельством связано и появление в объемной модели [11] острого максимума вблизи $V_{g}=0$, превышающего экспериментальные значения, обусловленного быстрым ростом объемной концентрации дырок в диэлектрике при исчезновении дрейфового члена в стоке дырок на МФГ. Таким образом, можно сделать вывод, что начальный плавный рост сдвига порогового напряжения и его обеих составляющих при ИО при небольших полях $E<(1-2) \mathrm{MB} /$ см лучше описывается настоящей моделью с пограничным слоем, тогда как для описания падения при более высоких полях необходимо привлекать объемную модель.

Для расчета сдвига порогового напряжения при отрицательном смещении в настоящей модели учитывалась генерация дырок при ИО в пограничном слое. Это позволило не учитывать реакции с образованием и участием нейтральных атомов водорода $\mathrm{H}^{0}$, как это было сделано в модели [11], поскольку, согласно расчетам [15,16], зарядовое состояние $\mathrm{H}^{0}$ нестабильно как в $\mathrm{SiO}_{2}$ [15], так и на МФГ $\mathrm{Si}-\mathrm{SiO}_{2}$ [16].

Зависимость сдвига порогового напряжения от толщины подзатворного диэлектрика при ИО вида $\Delta V_{i t} \sim d^{n}$ имеет показатель степени $\mathrm{n}$, который изменяется в разных работах, как правило, от 1 до 2 [3-5]. Считается, что степенной показатель определяется распределением дырочных ловушек по глубине диэлектрика - при равномерном распределении $n=2$, а при локализации в тонком слое вблизи МФГ $\mathrm{Si}-\mathrm{SiO}_{2} n=1$. В настоящей модели, несмотря на локализацию ловушек в тонком пограничном слое, показатель изменяется от $n \cong 2$ при малых толщинах диэлектрика и дозах ИО до $n \cong 1$ при больших толщинах и дозах. Показатель $n=2$ обусловлен в модели учетом потока дырок в пограничный слой со всей толщины подзатворного диэлектрика. Уменьшение показателя при больших толщинах и дозах происходит вследствие появления нелинейности при больших концентрациях дырок, захваченных пограничным слоем.

\section{5. Заключение}

Разработана новая количественная модель влияния смещения затвора на пороговое напряжение МОПструктур при ионизирующем облучении, базирующаяся на учете захвата дырок в тонком пограничном слое подзатворного диэлектрика на МФГ с кремниевой подложкой. Модель позволяет удовлетворительно описать плавный рост порогового напряжения с напряжением смещения на затворе - примерно линейный от дозы для поверхностной составляющей и нелинейный для объемной составляющей. Сдвиг порогового напряжения при отрицательном напряжении на затворе моделируется на основе учета генерации дырок в пограничном слое при ионизирующем облучении. Модель позволяет объяснить зависимость сдвига порогового напряжения от толщины оксида с изменением показателя степени от $\sim 2$ при малых толщинах диэлектрика и дозах ИО до $\sim 1$ при больших толщинах и дозах.

\section{Список литературы}

[1] К.И. Таперо, В.Н. Улимов, А.М. Членов. Радиационные эфбекты в кремниевых интегральных схемах космического применения (М., БИНОМ, 2012).

[2] В.С. Першенков, В.Д. Попов, А.В. Шальнов. Поверхностные радиационные эббекты в ИМС (М., Энергоатомиздат, 1988).

[3] D.M. Fleetwood. IEEE Trans. Nucl. Sci., 60 (3), 1706 (2013).

[4] J.R. Schwank, M.R. Shaneyfelt, D.M. Fleetwood, J.A. Felix, P.E. Dodd, P. Paillet, V. Ferlet-Cavrois. IEEE Trans. Nucl. Sci., 55 (4), 1833 (2008).

[5] T.R. Oldham, F.B. McLean. IEEE Trans. Nucl. Sci., 50 (3), 483 (2003).

[6] F.B. McLean. IEEE Trans. Nucl. Sci., 27 (6), 1651 (1980).

[7] M.R. Shaneyfelt, J.R. Schwank, D.M. Fleetwood, P.S. Winokur, K.L. Hughes, F.W. Sexton. IEEE Trans. Nucl. Sci., 37 (6), 1632 (1990).

[8] В.А. Гуртов, А.Н. Назаров, Н.В. Травков. ФТП, 24 (6), 969 (1990).

[9] М.Н. Левин, А.В. Татаринцев, В.А. Макаренко, В.Р. Гитлин. Микроэлектроника, 35 (6), 382 (2006).

[10] О.В. Александров. ФТП, 48 (4), 523 (2014).

[11] О.В. Александров. ФТП, 49 (6), 793 (2015).

[12] А П. Барабан, В.В. Булавинов, П.П. Коноров. Электроника слоев $\mathrm{SiO}_{2}$ на кремнии (Л., ЛГУ, 1988).

[13] S.J. Wang, J.M. Sung, S.A. Lyon. Appl. Phys. Lett., 52 (17), 1431 (1988).

[14] P.U. Kenkare, S.A. Lyon. Appl. Phys. Lett., 55 (22), 2328 (1989). 
[15] P.E. Bunson, M. Di Ventra, S.T. Pantelides, R.D. Schrimpf, K.F. Galloway. IEEE Trans. Nucl. Sci., 46 (6), 1568 (1999).

[16] S.N. Rashkeev, D.M. Fleetwood, R.D. Schrimpf, S.T. Pantelides. Phys. Rev. Lett., 87 (16), 165506 (2001).

[17] R.C. Hughes. Phys. Rev. Lett., 30 (26), 1333 (1973).

[18] R.C. Hughes. Phys. Rev. B, 15 (4), 2012 (1977).

[19] J.M. Benedetto, H.E. Boesch. IEEE Trans. Nucl. Sci., 33 (6), 1318 (1986).

[20] R.J. Krantz, L.W. Aukerman, T.C. Zietlow. IEEE Trans. Nucl. Sci., 34 (6), 1196 (1987).

[21] H.E. Boesch, F.B. McLean, J.M. Benedetto, J.M. McGarrity. IEEE Trans. Nucl. Sci., 33 (6), 1191 (1986).

[22] P.J. McWhorter, P.S. Winokur. Appl. Phys. Lett., 48 (2), 133 (1986).

[23] P.S. Winokur, H.E. Boesch, Jr., J.M. McGarrity, F.B. McLean. IEEE Trans. Nucl. Sci., 24 (6), 2113 (1977).

[24] P.S. Winokur, E.B. Errett, D.M. Fleetwood, P.V. Dressendorfer, D.C. Turpin. IEEE Trans. Nucl. Sci., 32 (6), 3954 (1985).

[25] J.R. Schwank, P.S. Winokur, F.W. Sexton, D.M. Fleetwood, J.H. Perry, P.V. Dressendorfer, D.T. Sanders, D.C. Turpin. IEEE Trans. Nucl. Sci., 33 (6), 1178 (1986).

Редактор Г.А. Оганесян

\section{Model of influence of gate bias on MOS-structures at ionizing radiation}

\section{O.V. Aleksandrov, S.A. Mokrushina}

\section{St. Petersburg State Electrotechnical University „LETI", 197376 St. Petersburg, Russia}

Abstract The new quantitative model of gate bias influence on the threshold shift of MOS-structures at ionizing radiation which is based on the accounting of holes trapping from whole volume of gate dielectric with hydrogen free and hydrogen containing traps in the thin border layer of on interface with a silicon substrate is developed. The model allows to describe the smooth growth of threshold shift with gate bias - approximately linear from a dose for a surface component and nonlinear for a volume component. The threshold shift at a negative gate bias is modeled on the basis of the accounting of holes generation at ionizing radiation in the border layer. 